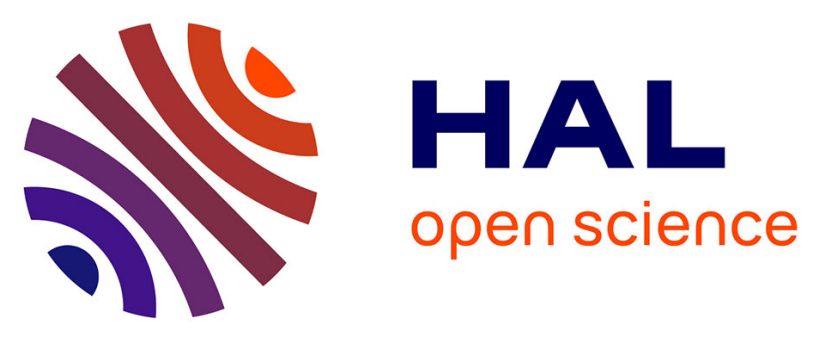

\title{
The ubiquitin-proteasome and the mitochondria-associated apoptotic pathways are sequentially downregulated during recovery after immobilization-induced muscle atrophy
}

Emilie Vazeille, Audrey Codran, Agnes Claustre, Julien Averous, Anne Listrat, Daniel D. Bechet, Daniel Taillandier, Dominique Dardevet, Didier Attaix, Lydie Combaret

\section{- To cite this version:}

Emilie Vazeille, Audrey Codran, Agnes Claustre, Julien Averous, Anne Listrat, et al.. The ubiquitinproteasome and the mitochondria-associated apoptotic pathways are sequentially downregulated during recovery after immobilization-induced muscle atrophy. AJP - Endocrinology and Metabolism, 2008, 295 (5), pp.E1181-E1190. 10.1152/ajpendo.90532.2008 . hal-02660018

\section{HAL Id: hal-02660018 https://hal.inrae.fr/hal-02660018}

Submitted on 30 May 2020

HAL is a multi-disciplinary open access archive for the deposit and dissemination of scientific research documents, whether they are published or not. The documents may come from teaching and research institutions in France or abroad, or from public or private research centers.
L'archive ouverte pluridisciplinaire HAL, est destinée au dépôt et à la diffusion de documents scientifiques de niveau recherche, publiés ou non, émanant des établissements d'enseignement et de recherche français ou étrangers, des laboratoires publics ou privés. 
Emilie Vazeille, Audrey Codran, Agnès Claustre, Julien Averous, Anne Listrat, Daniel Béchet, Daniel Taillandier, Dominique Dardevet, Didier Attaix and Lydie Combaret

Am J Physiol Endocrinol Metab 295:1181-1190, 2008. First published Sep 23, 2008;

doi:10.1152/ajpendo.90532.2008

You might find this additional information useful...

This article cites 44 articles, 25 of which you can access free at:

http://ajpendo.physiology.org/cgi/content/full/295/5/E1181\#BIBL

This article has been cited by 4 other HighWire hosted articles:

XIAP Reduces Muscle Proteolysis Induced by CKD

J. Hu, J. Du, L. Zhang, S. R. Price, J. D. Klein and X. H. Wang

J. Am. Soc. Nephrol., July 1, 2010; 21 (7): 1174-1183.

[Abstract] [Full Text] [PDF]

Molecular and phenotypic characterization of a mouse model of oculopharyngeal muscular dystrophy reveals severe muscular atrophy restricted to fast glycolytic fibres

C. Trollet, S. Y. Anvar, A. Venema, I. P. Hargreaves, K. Foster, A. Vignaud, A. Ferry, E.

Negroni, C. Hourde, M. A. Baraibar, P. A. C. 't Hoen, J. E. Davies, D. C. Rubinsztein, S. J.

Heales, V. Mouly, S. M. van der Maarel, G. Butler-Browne, V. Raz and G. Dickson

Hum. Mol. Genet., June 1, 2010; 19 (11): 2191-2207.

[Abstract] [Full Text] [PDF]

The microRNA miR-696 regulates PGC-1\{alpha\} in mouse skeletal muscle in response to physical activity

W. Aoi, Y. Naito, K. Mizushima, Y. Takanami, Y. Kawai, H. Ichikawa and T. Yoshikawa

Am J Physiol Endocrinol Metab, April 1, 2010; 298 (4): E799-E806.

[Abstract] [Full Text] [PDF]

Alterations of protein turnover underlying disuse atrophy in human skeletal muscle

S. M. Phillips, E. I. Glover and M. J. Rennie

J Appl Physiol, September 1, 2009; 107 (3): 645-654.

[Abstract] [Full Text] [PDF]

Updated information and services including high-resolution figures, can be found at:

http://ajpendo.physiology.org/cgi/content/full/295/5/E1181

Additional material and information about AJP - Endocrinology and Metabolism can be found at: http://www.the-aps.org/publications/ajpendo

This information is current as of September 2, 2010 .

AJP - Endocrinology and Metabolism publishes results of original studies about endocrine and metabolic systems on any level of organization. It is published 12 times a year (monthly) by the American Physiological Society, 9650 Rockville Pike, Bethesda MD 20814-3991. Copyright @ 2008 by the American Physiological Society. ISSN: 0193-1849, ESSN: 1522-1555. Visit our website at http://www.the-aps.org/. 


\title{
The ubiquitin-proteasome and the mitochondria-associated apoptotic
} pathways are sequentially downregulated during recovery after
immobilization-induced muscle atrophy

\author{
Emilie Vazeille, ${ }^{1,2}$ Audrey Codran,,${ }^{1,2}$ Agnès Claustre, ${ }^{1,2}$ Julien Averous, ${ }^{1,2}$ Anne Listrat, ${ }^{3}$ Daniel Béchet, ${ }^{1,2}$ \\ Daniel Taillandier, ${ }^{1,2}$ Dominique Dardevet, ${ }^{1,2}$ Didier Attaix, ${ }^{1,2}$ and Lydie Combaret ${ }^{1,2}$ \\ ${ }^{1}$ Unité de Nutrition Humaine, UMR1019, Institut National de la Recherche Agronomique, Saint Genes Champanelle; ${ }^{2}$ Centre \\ de Recherche en Nutrition Humaine, Clermont-Ferrand; and ${ }^{3}$ Unité de Recherche sur les Herbivores, UR1213, Institut \\ National de la Recherche Agronomique, Saint Genes Champanelle, France
}

Submitted 23 June 2008; accepted in final form 20 September 2008

Vazeille E, Codran A, Claustre A, Averous J, Listrat A, Béchet D, Taillandier D, Dardevet D, Attaix D, Combaret L. The ubiquitinproteasome and the mitochondria-associated apoptotic pathways are sequentially downregulated during recovery after immobilization-induced muscle atrophy. Am J Physiol Endocrinol Metab 295: E1181-E1190, 2008. First published September 23, 2008; doi:10.1152/ajpendo.90532.2008.Immobilization produces morphological, physiological, and biochemical alterations in skeletal muscle leading to muscle atrophy and long periods of recovery. Muscle atrophy during disuse results from an imbalance between protein synthesis and proteolysis but also between apoptosis and regeneration processes. This work aimed to characterize the mechanisms underlying muscle atrophy and recovery following immobilization by studying the regulation of the mitochondria-associated apoptotic and the ubiquitin-proteasome-dependent proteolytic pathways. Animals were subjected to hindlimb immobilization for 4-8 days (I4 to I8) and allowed to recover after cast removal for 10-40 days (R10 to R40). Soleus and gastrocnemius muscles atrophied from I4 to I8 to a greater extent than extensor digitorum longus and tibialis anterior muscles. Gastrocnemius muscle atrophy was first stabilized at R10 before being progressively reduced until R40. Polyubiquitinated proteins accumulated from I4, whereas the increased ubiquitination rates and chymotrypsin-like activity of the proteasome were detectable from I6 to I8. Apoptosome and caspase-3 or -9 activities increased at I6 and I8, respectively. The ubiquitinproteasome-dependent pathway was normalized early when muscle stops to atrophy (R10). By contrast, the mitochondria-associated apoptotic pathway was first downregulated below basal levels when muscle started to recover at R15 and completely normalized at R20. Myf 5 protein levels decreased from I4 to I8 and were normalized at R10. Altogether, our results suggest a two-stage process in which the ubiquitin-proteasome pathway is rapidly up- and downregulated when muscle atrophies and recovers, respectively, whereas apoptotic processes may be involved in the late stages of atrophy and recovery.

ubiquitin-proteasome-dependent pathway; disuse; intrinsic apoptotic pathway; protein breakdown; remodeling

MUSCLE WASTING IS OBSERVED in numerous conditions (aging, immobilization, chronic disorders or diseases). The main function of skeletal muscle is to provide power and strength for locomotion and posture, but this tissue is also the major reservoir of body proteins. Thus, although the loss of muscle proteins has positive effects in the short term, an uncontrolled and sustained muscle wasting impairs movement, leads to

Address for reprint requests and other correspondence: L. Combaret, Unité de Nutrition Humaine, Institut National de la Recherche Agronomique, Centre de Recherche de Clermont-Ferrand Theix, 63122 Ceyrat, France (e-mail: combaret@clermont.inra.fr). difficulties in performing daily activities, and has detrimental metabolic consequences. The resulting weakness increases the incidence of falls and the length of recovery. Immobilization can result from this muscle weakness and itself produces further morphological, physiological, and biochemical alterations in skeletal muscle fibers.

Muscle protein loss results from an imbalance between protein synthesis and breakdown rates but also from an imbalance between apoptotic and differentiation-regeneration processes. The ubiquitin (Ub)-proteasome pathway is systematically activated when muscle atrophies extensively and is involved in the breakdown of the major contractile proteins. Basically, there are two main steps in the pathway: 1) covalent attachment of a polyUb degradation signal to the substrate and 2) specific recognition of the polyUb chain and subsequent breakdown of the targeted proteins by the $26 \mathrm{~S}$ proteasome (2). We and others have previously shown that hindlimb suspension induces atrophy and loss of protein of the rat soleus muscle as a result of an activation of the Ub-proteasome proteolytic pathway $(5,17,39)$. Similar observations were reported in muscles of rats exposed to spaceflight or denervation $(20,40)$.

Immobilization induces also a reduction of myocyte number and a decrease of satellite cell activity $(19,31)$, suggesting an activation of apoptosis. Apoptosis is a physiological mechanism involved in morphogenesis, the adjustment of cell number, the elimination of abnormal cells, and the regulation of the immune system and plays a key role in pathophysiological muscle cell loss. The degree of apoptosis depends on the balance between the activation of pro- and antiapoptotic genes. In general, shifts in this balance toward increasing proapoptotic genes activate a cascade of caspases and are believed to promote muscle atrophy. Two main apoptotic pathways have been involved in caspase activation. The extrinsic pathway is triggered by the activation of a family of death receptors at the cell surface and controls the activation of caspase- 8 . The intrinsic pathway is triggered by the release of killer proteins, such as cytochrome $c$ and smac/Diablo, and is sensitive to intracellular stress, such as oxidative stress. In this latter pathway (also called mitochondrial apoptotic pathway), apoptosis is initiated by the release of cytochrome $c$ from the mitochondria, which then forms a complex (called apopto-

\footnotetext{
The costs of publication of this article were defrayed in part by the payment of page charges. The article must therefore be hereby marked "advertisement" in accordance with 18 U.S.C. Section 1734 solely to indicate this fact.
} 
some) with the apoptotic protease activating factor-1 (Apaf-1), and the pro-caspase- 9 , leading to activation of caspase- 9 and caspase-3 (25). The mitochondria-associated apoptotic signaling is believed to be physiologically important in regulating disuse-induced muscle atrophy $(1,7,9,25,33)$. Evidence for apoptosis during disuse includes increases in the frequency of nuclei with DNA strand breaks and in the expression of proapoptotic genes, such as Bax, caspase 3, apoptosis-inducing factor, and Apaf-1 $(7,37)$. In addition, an increased expression of genes involved in both Ub-proteasome-dependent proteolysis and apoptosis prevailed in human muscle biopsies following $48 \mathrm{~h}$ of immobilization (43). However, the links between Ub-proteasome-dependent proteolysis and apoptosis during skeletal muscle atrophy are not fully understood.

Very few studies have investigated the mechanisms involved in muscle recovery following disuse. We previously showed that the Ub-proteasome dependent pathway is activated during the early stages of recovery following hindlimb suspension and completely normalized following 7 days of reloading (38). Human skeletal muscle disuse atrophy and subsequent recovery are also linked to the regulation of the expression of the $20 \mathrm{~S}$ proteasome subunits and the muscle-specific proteolytic genes MAFbx and MuRF1 (22). Although these studies are important contributions to the literature, these alterations were mostly explored at the mRNA level. The role of apoptosis in skeletal muscle regeneration is totally unclear. Moresi et al. (29) reported that inhibition of caspase-3 improved muscle regeneration, and studies suggest that caspase-3 activity is required for the differentiation of $\mathrm{C} 2 \mathrm{C} 12$ muscle cells (14). In addition, apoptotic mechanisms are involved in the modulation of the myonuclear number during chronic unloading and reloading (32). Therefore, we hypothesized 1 ) that the mitochondria-associated apoptotic pathway should be activated along the Ub-proteasome-dependent proteolysis in immobilized muscles and 2) that both systems could play a key role during muscle mass recovery following the muscle wasting period.

\section{EXPERIMENTAL PROCEDURES}

Animals. The present study was approved by the Animal Care and Use Committee at the Institut National de la Recherche Agronomique (INRA) and adhered to the current legislation on animal experimentation in France. Male Wistar rats aged 8 mo (Charles River Laboratories, L'Arbresle, France) were housed individually under controlled environmental conditions (temperature $22^{\circ} \mathrm{C} ; 12$-h dark period starting at $8 \mathrm{~h}$ ), fed a basal diet ad libitum, and given free access to water. Macronutrient composition of basal diet was (in $\mathrm{g} / \mathrm{kg}$ diet) 470 wheat flour, 152 casein, 100 sucrose, 134 lactose, 30 colza oil, 27 peanut oil, 3 sunflower oil, 35 AIN93 mineral mix, 10 AIN93 vitamin mix, and 35 cellulose. After a 3-wk adaptation period, rats were anesthetized with forene inhalation and subjected to unilateral hindlimb immobilization via an Orfit-soft plaque (Gibaud). The foot was positioned in plantar extension to induce maximal atrophy of the gastrocnemius and the soleus muscles (24). Experiment 1 was performed to ensure that the muscles from the contralateral noncasted leg can be used as controls in all experiments. In that experiment, 8 rats were subjected to immobilization for 8 days and 16 rats were not casted. The noncasted rats were divided into two distinct control groups either fed ad libitum $(n=8)$ or pair-fed to the group of casted rats $(n=8)$. This experiment showed that muscle masses from the nonimmobilized leg of casted rats were not significantly different from those of ad libitum or pair-fed control noncasted rats. Therefore, the contralateral nonimmobilized leg of casted rats served as the control. In experiment 2, 40 rats were allocated into eight groups. Immobilization was imposed for
4 (I4), 6 (I6), or 8 (I8) days. For skeletal muscle recovery studies, casts were removed after 8 days of immobilization under anesthesia (forene inhalation) and animals were allowed to recover for 10 (R10), 15 (R15), 20 (R20), 30 (R30), and 40 (R40) days. At the end of the immobilization or recovery periods, animals were euthanized under pentobarbital sodium anesthesia $(50 \mathrm{mg} / \mathrm{kg}$ ip). Hindlimb skeletal muscles [soleus, extensor digitorum longus (EDL), and tibialis anterior] were carefully dissected, weighed, and frozen in liquid nitrogen. Gastrocnemius muscles were also carefully excised and weighed. The central part of gastrocnemius samples was frozen in isopentane chilled at $-196^{\circ} \mathrm{C}$ by liquid nitrogen for apoptotic nuclear measurements. The remaining muscle was finely pulverized in liquid nitrogen and stored at $-80^{\circ} \mathrm{C}$ until further analyses.

Processing of the tissues and apoptotic nuclei measurements. Frozen sections were cut into $10-\mu \mathrm{m}$-thick cross sections with a cryostat (Cryo-star HM560MV, Microm International). The DNA fragmentation of nuclei was monitored using a TUNEL (terminal deoxynucleotidyl transferase biotin-dUTP nick-end labeling) fluorescent detection kit (Roche Applied Science), according to the manufacturer's instructions.

Measurement of proteasome and apoptosome activities. Powder $(150 \mathrm{mg})$ of gastrocnemius muscles from control and immobilized hindlimb at each time point was homogenized in 10 volumes of an ice-cold buffer ( $\mathrm{pH}$ 6.5) containing 50 mM PIPES, 2 mM EDTA ( $\mathrm{pH}$ 8.0), 1\% 3[(3-cholamidopropyl)dimethylammonio]-propanesulfonic acid (CHAPS), $5 \mathrm{mM}$ DTT, and protease inhibitors $(10 \mu \mathrm{g} / \mathrm{ml} \mathrm{leu-}$ peptin, $10 \mu \mathrm{g} / \mathrm{ml}$ pepstatin, $10 \mu \mathrm{g} / \mathrm{ml}$ aprotinin, $2 \mathrm{mM}$ PMSF) Extracts were centrifuged at $10,000 \mathrm{~g}$ for $20 \mathrm{~min}$ at $4^{\circ} \mathrm{C}$. Equal amounts of each supernatant from immobilized or control extracts at the same time point were pooled and then centrifuged at $100,000 \mathrm{~g}$ for $1 \mathrm{~h}$ at $4^{\circ} \mathrm{C}$. The resulting supernatants were concentrated on Ultracel-100 membrane (Ultra-15 Centrifugal Filter Units, Amicon) to enrich the preparation in proteasomes or apoptosome complexes, which exhibit high molecular mass $(700-1,400 \mathrm{kDa})$. Protein concentration of these concentrates was determined according to Lowry et al. (27). Concentrated extracts were loaded onto 10-40\% sucrose gradients in a buffer containing 0.1\% CHAPS, $20 \mathrm{mM}$ HEPES, and $5 \mathrm{mM}$ DTT. Samples were centrifuged at $100,000 \mathrm{~g}$ for $17 \mathrm{~h}$ at $4^{\circ} \mathrm{C}$ and gradients were separated in 500- $\mu$ l fractions.

Apoptosome complexes copurified with proteasomes on $10-40 \%$ sucrose gradients (8). The same fractions were therefore tested for the chymotrypsin-like activity of the proteasome or the apoptosomelinked caspase- 9 activity by measuring the hydrolysis of the fluorogenic substrates succinyl-Leu-Leu-Val-Tyr-7-amido-4-methylcoumarin (LLVY-AMC) (Sigma) or $\mathrm{N}$-acetyl-Leu-Glu-His-Asp-7-amino-4methylcoumarin (LEHD-AMC) (Biomol), respectively $(4,10)$. To measure the chymotrypsin-like activity of the proteasome, $15 \mu \mathrm{l}$ of each fraction was added to $60 \mu \mathrm{l}$ of medium containing $50 \mathrm{mM}$ Tris (pH 8.0), $10 \mathrm{mM} \mathrm{MgCl} 2,1 \mathrm{mM}$ DTT, $2 \mathrm{U}$ apyrase, and $300 \mu \mathrm{M}$ LLVY-AMC with or without the proteasome inhibitor MG132 (40 $\mu \mathrm{M}$, Affiniti). To measure the apoptosome-linked caspase- 9 activity, $25 \mu \mathrm{l}$ of each fraction were diluted to $50 \mu \mathrm{l}$ with a buffer containing $20 \mathrm{mM}$ HEPES (pH 7.4), $10 \mathrm{mM} \mathrm{NaCl}, 1.5 \mathrm{mM} \mathrm{MgCl}_{2}, 20 \%$ glycerol, $0.1 \%$ Triton X-100, and $1 \mathrm{mM}$ DTT (buffer A). Fractions were then incubated with $50 \mu \mathrm{l}$ of a reaction buffer (buffer $B$ ) containing $50 \mathrm{mM}$ PIPES, $0.1 \mathrm{mM}$ EDTA, $10 \%$ glycerol, $10 \mathrm{mM}$ DTT, and $50 \mu \mathrm{M}$ of LEHD-AMC with or without the caspase-9 inhibitor $N$-acetyl-Leu-Glu-His-Asp-CHO (LEHD-CHO) $(50 \mu \mathrm{M}$, Biomol). Both activities were determined by measuring the accumulation of the fluorogenic cleavage product (methylcoumaryl-amide, AMC) using a luminescence spectrometer FLX800 (Biotek) during 45 $\min$ at $380-\mathrm{nm}$ excitation wavelength and 440-nm emission wavelength. The chymotrypsin-like activity of the proteasome and the apoptosome-linked caspase-9 activity were measured by calculating the difference between arbitrary fluorescence units recorded with or without the specific inhibitors in the reaction medium. The final data were corrected by the amount of protein loaded onto the gradient. The 
time course for the accumulation of AMC after hydrolysis of the substrate in each fraction was analyzed by linear regression to calculate activities, i.e., the slopes of best fit of accumulated AMC vs. time.

Ubiquitination rates. Soluble proteins were extracted as described (10). Briefly, powder ( $350 \mathrm{mg}$ ) of gastrocnemius muscles was homogenized in an ice-cold buffer containing $50 \mathrm{mM}$ Tris $\cdot \mathrm{HCl}(\mathrm{pH} 7.5), 1$ $\mathrm{mM}$ DTT, $1 \mathrm{mM}$ EDTA, $1 \mathrm{mM}$ PMSF, $10 \mu \mathrm{g} / \mathrm{ml}$ pepstatin A, and 10 $\mu \mathrm{g} / \mathrm{ml}$ leupeptin. The homogenates were centrifuged $(10,000 \mathrm{~g}, 10$ $\min , 4^{\circ} \mathrm{C}$ ) and the resulting supernatants were centrifuged at 100,000 $g$ for $60 \mathrm{~min}$ at $4^{\circ} \mathrm{C}$. Protein concentration was determined as described (27). The final supernatants were stored at $-80^{\circ} \mathrm{C}$ until use. Rates of ubiquitination of tissue proteins were determined by a method slightly modified from our previous work (10). Soluble proteins from gastrocnemius muscles were incubated at $37^{\circ} \mathrm{C}$ with a reaction buffer containing $50 \mathrm{mM}$ Tris $\cdot \mathrm{HCl}(\mathrm{pH} 7.5), 1 \mathrm{mM}$ DTT, 2

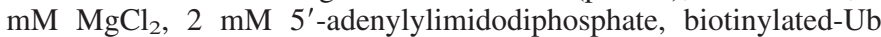
(2.5 mM, Tebu bio), and $\mathrm{Ub}$ aldehyde (4.5 mM, Boston Biochem) (34). The reaction was stopped after $5 \mathrm{~min}$ by the addition of Laemmli buffer. Pilot studies showed that conjugation rates were linear for this period of time and that the concentration of biotinylated-Ub was in significant excess of any endogenous Ub. After incubation, Ub conjugates were then resolved from free Ub by SDS-PAGE on $10 \%$ gels and visually detected with a streptavidin/biotin detection kit (Novagen). High molecular weight biotinylated-conjugates were visualized on autoradiographic films (GE Healthcare), and the biotin-Ub bound to protein substrates was determined by densitometric analysis using the Image $J$ software. The rates of ubiquitination were calculated by using the quantification of the accumulation of high molecular weight conjugates between 0 and 5 min and expressed as arbitrary units per minute.

Total caspase-3 and -9 activities. Caspase-3 and -9 activities were assessed on total cytosolic protein extracts. Powder $(150 \mathrm{mg})$ of gastrocnemius muscles was homogenized in an ice-cold buffer $A$ (see above) as described in Siu et al. (37). Extracts were centrifuged at $1,500 \mathrm{~g}$ for $5 \mathrm{~min}$ at $4^{\circ} \mathrm{C}$ and the resulting supernatants were subjected to three further centrifugations at $3,500 \mathrm{~g}$ for $5 \mathrm{~min}$ at $4^{\circ} \mathrm{C}$. The last supernatants were stored as total cytosolic protein extracts at $-80^{\circ} \mathrm{C}$. A protease inhibitor cocktail containing $104 \mathrm{mM} \mathrm{4-(2-aminoethyl)-}$ benzenesulfonyl fluoride, $0.08 \mathrm{mM}$ aprotinin, $2 \mathrm{mM}$ leupeptin, $4 \mathrm{mM}$ bestatin, $1.5 \mathrm{mM}$ pepstatin A, and $1.4 \mathrm{mM} \mathrm{E-64} \mathrm{(Sigma)} \mathrm{was} \mathrm{added} \mathrm{to}$ a small part of these supernatants, which were then stored at $-80^{\circ} \mathrm{C}$ for subsequent determination of protein levels for X-linked inhibitory apoptotic protein (XIAP) (see next paragraph). Protein concentration was determined according to Lowry et al. (27). Caspase-3 and -9 activities were assessed by use of fluorogenic substrates. Briefly, 25 $\mu \mathrm{l}$ of the total cytosolic protein extracts was diluted to $50 \mu \mathrm{l}$ with buffer $A$ and incubated with $50 \mu$ l of buffer $B$ (see above) containing $50 \mu \mathrm{M}$ of Ac-Asp-Glu-Val-Asp-AMC (DEVD-AMC, Calbiochem) or LEHD-AMC for caspase-3 and -9, respectively. Reactions were performed with or without $50 \mu \mathrm{M}$ of inhibitors of caspase- $3 \mathrm{~N}$-acetylAsp-Met-Gln-Asp-CHO (DMQD-CHO, Calbiochem) or caspase-9 (LEHD-CHO). Caspase activities were determined by measuring the accumulation of AMC with a luminescence spectrometer FLX800 (Biotek) during $1 \mathrm{~h}$ at 380-nm excitation wavelength and 460-nm emission wavelength. The caspase- 3 and -9 activities were measured by calculating the difference between arbitrary fluorescence units recorded with or without the specific inhibitors in the reaction medium. The final data were corrected by the amount of proteins. The time course for the accumulation of AMC after hydrolysis of the substrate was analyzed by linear regression to calculate activities, i.e., the slopes of best fit of accumulated AMC vs. time.

Western blot analyses. The abundance of the apoptosome complexes was assessed by measurements of the caspase- 9 and the APAF-1 protein levels in the fractions containing the apoptosomelinked caspase 9 activity at I8. Forty $\mu$ l of these fractions were separated on 15 and $7.5 \%$ (wt/vol) acrylamide gels for caspase-9 and APAF-1, respectively, and transferred on polyvinylidene difluoride
(PVDF) membranes (GE Healthcare). Antibodies against caspase-9 and APAF-1 (Cell Signaling) were used at 1:500 dilutions. The amount of protein levels for the antiapoptotic XIAP was assessed by immunoblotting on supernatants from the cytosolic protein extracts (see above). Fifty micrograms of total protein extract were separated on $7.5 \%$ acrylamide gels and transferred on PVDF membranes (GE Healthcare). Antibody against XIAP (Cell Signaling) was used at 1:1,000 dilution.

The accumulation of Ub protein conjugates was assessed by immunoblotting on myofibrillar protein extracts. Powder $(150 \mathrm{mg})$ of gastrocnemius muscles was homogenized in an ice-cold buffer (buffer C) containing $5 \mathrm{mM}$ Tris $\cdot \mathrm{HCl}(\mathrm{pH} 7.5), 5 \mathrm{mM}$ EDTA, $\mathrm{pH} 8,1 \mathrm{mM}$ PMSF, $0.25 \mathrm{mM}$ tosyl-lysylchloromethane, $5 \mathrm{mM} N$-ethyl-maleimide, $5 \mu \mathrm{g} / \mathrm{ml}$ leupeptin, and $5 \mu \mathrm{g} / \mathrm{ml}$ soybean trypsin inhibitor (10). Homogenates were centrifuged for $5 \mathrm{~min}\left(1,500 \mathrm{~g}, 4^{\circ} \mathrm{C}\right)$ to pellet myofibrillar proteins, which were then washed three times in buffer $C$ containing $1 \%$ Triton $\mathrm{X}-100$. Myofibrillar proteins were then resuspended in $8 \mathrm{M}$ urea/5 $\mathrm{mM}$ Tris $\cdot \mathrm{HCl}(\mathrm{pH} 7.5)$. Protein concentration was determined as described (27). The accumulation of Ub-protein conjugates was measured on $25 \mu \mathrm{g}$ of myofibrillar proteins separated on $7.5 \%$ (wt/vol) acrylamide gels and transferred onto PVDF membranes. The FK1 antibody (Affiniti), which recognizes polyUb chains, was used at a 1:1,000 dilution.

The abundance of myf5 was assessed by Western blotting. Powder (100 mg) of gastrocnemius muscles from control and immobilized hindlimb at each time point was homogenized in $10 \mathrm{vol}$ of lysis buffer containing $20 \mathrm{mM}$ HEPES (pH 7.5); $25 \mathrm{mM} \beta$-glycerophosphate; 50 $\mathrm{mM} \mathrm{KCl} ; 0.2 \mathrm{mM}$ EDTA; $0.5 \mathrm{mM}$ sodium orthovanadate; $1 \mu \mathrm{g} / \mathrm{ml}$ each of pepstatin, leupeptin, and antipain; $1 \mathrm{mM}$ benzamidine; and 1 $\mathrm{mM}$ PMSF. After homogenization, $1 \%$ Triton wad added and the samples were subjected to freeze-thaw. The lysates were then centrifuged for $10 \mathrm{~min}$ at $16,000 \mathrm{~g}$, and the supernatants were collected. Protein concentration was determined as described (27). Fifty micrograms of total protein extract were separated on a $12 \%$ acrylamide gels and transferred on PVDF membranes (GE Healthcare). Antibody against myf5 (Santa Cruz Biotechnology) was used at 1/1,000 dilution. Signals were detected using the ECL + detection kit (GE Healthcare) after exposition onto radiographic film (Hyperfilm ECL, GE Healthcare).

Statistical analyses. All data are expressed as means \pm SE. Differences in muscle mass in experiment 1 were assessed by one-way ANOVA. In experiment 2, differences between control and immobilized muscles at each time point were assessed by paired Student's $t$-test. The evolution of the differences during the immobilization and the recovery periods in experiment 2 was determined by one-way ANOVA. Significance was defined at the 0.05 level. All tests were performed by using Statview (SAS Institute, Cary, NC).

\section{RESULTS}

Animal characteristics. Rats reduced their food intake by $30 \%$ (Fig. 1A) during the immobilization period, so that their body weight decreased by $12 \%$ at I8 (Fig. 1B). After cast removal, food intake increased progressively and was normalized ( $\sim 20 \mathrm{~g}$ of dry matter intake) after R20. However, the animals did not recover their initial body weight even at R40.

To ensure that the nonimmobilized contralateral leg of the rats may be used as control in all experiments, muscle masses from both the immobilized and the nonimmobilized leg of casted rats were compared with those from noncasted animals. Table 1 shows that gastrocnemius and soleus muscle masses from the nonimmobilized leg of the casted rats were not significantly different from those of ad libitum or pair-fed noncasted rats. This indicates that muscles from the contralateral leg did not hypertrophy because of overloading and that the skeletal muscle atrophy at I8 reflected a loss of muscle 

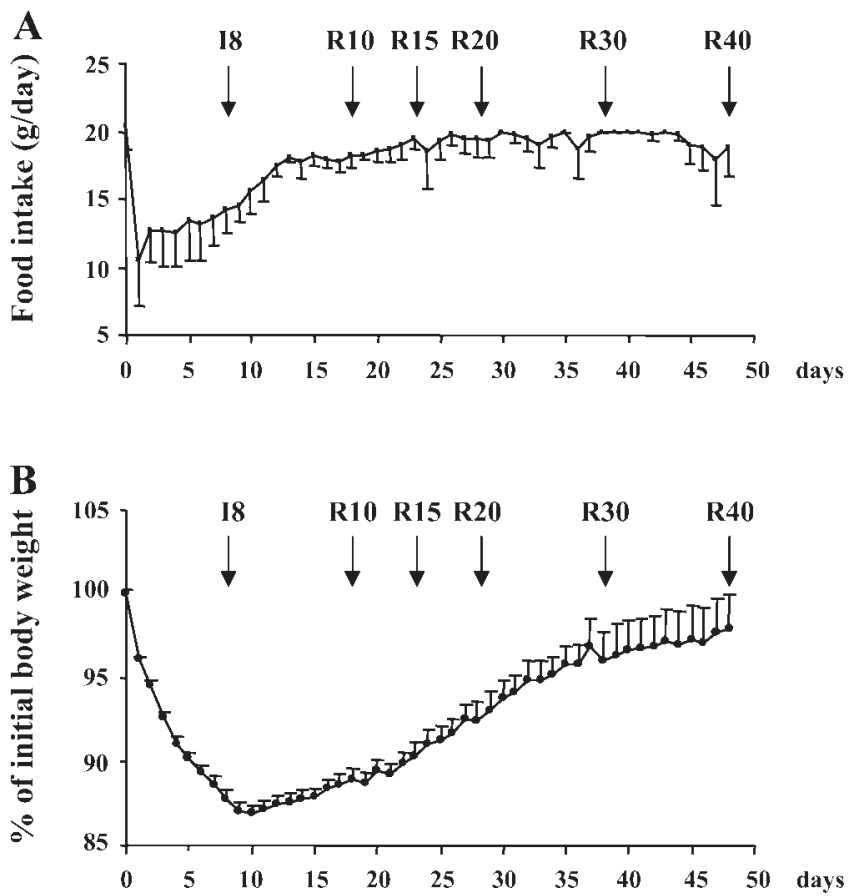

Fig. 1. Food intake and body weight of rats during immobilization and recovery. I8, 8 days of hindlimb immobilization; R10-R40, 10-40 days, respectively, of recovery from hindlimb immobilization after cast removal. Food intake $(A)$ and body weight $(B)$ are expressed in g/day and changes in \% of initial body weight, respectively. Data are means \pm SE for 5-10 animals.

mass in the immobilized leg. Therefore, muscles from the contralateral nonimmobilized leg were used as controls for all measurements.

Muscle atrophy and recovery. Hindlimb muscles atrophied progressively between I4 and I8 (Fig. 2). This atrophy reached $23 \%(P<0.0005), 30 \%(P<0.05), 11 \%(P<0.05)$, and $16 \%$ $(P<0.05),(P<0.05)$ at $\mathrm{I} 8$ for the gastrocnemius, the soleus, the EDL, and the tibialis anterior muscle, respectively. Thus the gastrocnemius and soleus muscles exhibited a greater atrophy at I8 than the tibialis anterior and EDL muscles.

After cast removal, the atrophy of the gastrocnemius, the soleus, and the EDL muscles first stabilized between I8 and R10. The atrophy of the gastrocnemius immobilized muscle remained significant until R30 vs. muscles from the noncasted leg (control muscles) (Fig. 2A). However, the level of atrophy was significantly reduced between I8 and R15 and a slow decrease prevails later on until R40. Similar observations prevailed for the soleus and the EDL muscles, although the degree of atrophy was diminished from R20 compared with I8

Table 1. Masses of the gastrocnemius and soleus muscles are not significantly affected by food restriction and casting in the contralateral leg

\begin{tabular}{|c|c|c|c|c|}
\hline & \multicolumn{2}{|c|}{ Noncasted Rats } & \multicolumn{2}{|c|}{ Casted Rats } \\
\hline & Ad Libitum & Pair-Fed & Control Leg & $\begin{array}{c}\text { Immobilized } \\
\text { Leg }\end{array}$ \\
\hline Gastrocnemius & $2.858 \pm 0.103^{\mathrm{a}}$ & $2.841 \pm 0.093^{\mathrm{a}}$ & $2.795 \pm 0.069^{\mathrm{a}}$ & $2.137 \pm 0.080^{\mathrm{b}}$ \\
\hline Soleus & $0.194 \pm 0.007^{\mathrm{a}}$ & $0.183 \pm 0.008^{a}$ & $0.180 \pm 0.013^{\mathrm{a}}$ & $0.124 \pm 0.005^{\mathrm{b}}$ \\
\hline
\end{tabular}

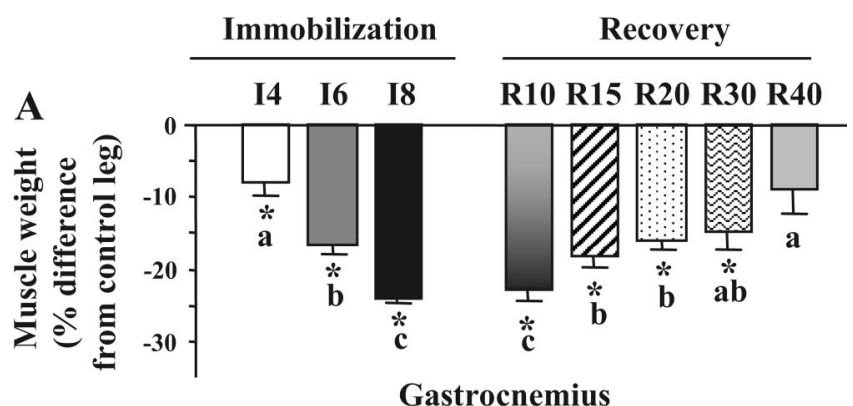

Gastrocnemius

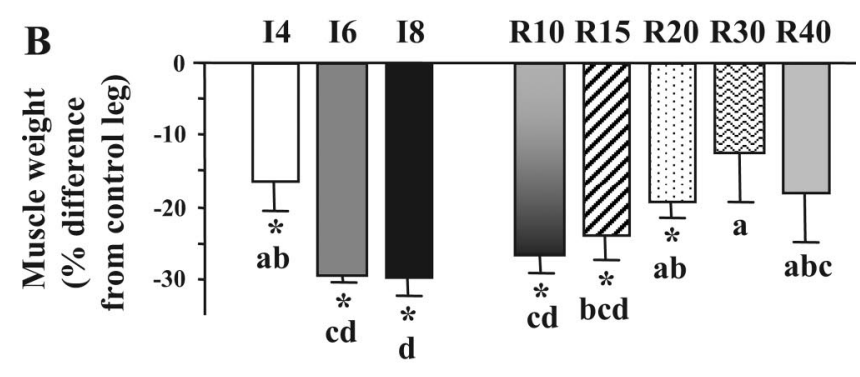

Soleus
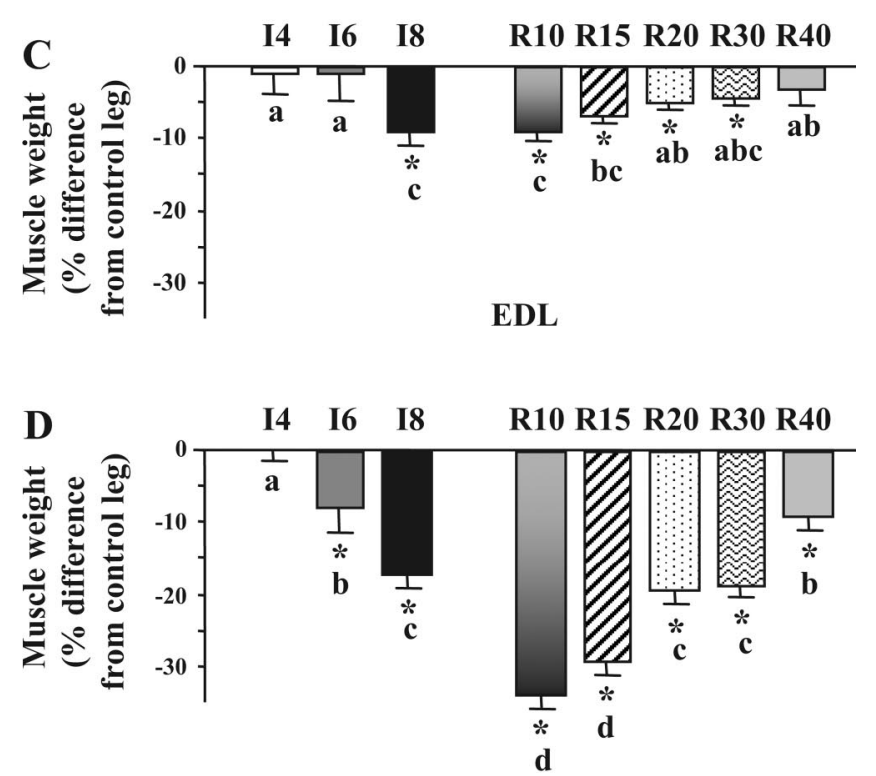

Tibialis anterior

Fig. 2. Hindlimb muscle atrophy and recovery following immobilization. Skeletal muscle atrophy of the gastrocnemius $(A)$, the soleus $(B)$, the extensor digitorum longus (EDL; $C$ ), and the tibialis anterior $(D)$ induced by immobilization is expressed in \% difference from the contralateral control uncasted leg. I4 and I6, 4 and 6 days, respectively, of hindlimb immobilization. Values are means $\pm \mathrm{SE}$ (vertical bars) for $n=5$ rats per group. Differences between control and immobilized muscles at each time point were assessed by the paired Student's $t$-test $(* P<0.05)$. The evolution of the differences during the immobilization and the recovery periods was determined by 1-way ANOVA. Bars with different letters are significantly different from each other $(P<0.05)$.

(Fig. 2, $B$ and $C$ ). The kinetic of recovery was completely different in the tibialis anterior muscle (Fig. $2 D$ ). Indeed, a large additional atrophy $(+97 \%, P<0.05)$ of this muscle occurred between I8 $(-17 \%, P<0.05)$ and R10 $(+33 \%, P<$ 
0.05). This induced a delay in the subsequent recovery. Indeed, the atrophy of the tibialis anterior muscle stabilized between $\mathrm{R} 10$ and R15 and decreased thereafter from R20 $(P<0.05$, R10 or R15 vs. R20). However, the atrophy was still significant at R40 between the muscles from the casted and the noncasted leg and was reduced below I8 levels only at R40.

The kinetics of muscle mass recovery clearly depend on the disuse model. Indeed, the mass of gastrocnemius or soleus muscles was completely normalized in 1 or $2 \mathrm{wk}$ of reloading after hindlimb suspension $(23,32,38)$. By contrast, castinduced immobilization is followed by a much longer period of recovery, with muscle mass accretion in the gastrocnemius starting only 2 wk after cast removal and being complete after 1 mo. Therefore, the study of the regulation of proteolytic and apoptotic pathways was performed by using time points flanking the gastrocnemius muscle mass stabilization and accretion stages.

Regulation of the Ub-proteasome dependent pathway. Previous studies suggest that the Ub-proteasome-dependent pathway was activated in several models of disuse based on mRNA or protein levels measurements $(5,17,24,38,39,44)$. Therefore, the regulation of this particular pathway was assessed by measuring ubiquitination rates, the resulting accumulation of $\mathrm{Ub}$ conjugates and proteasome activities. Figure $3 A$ shows that rates of ubiquitination increased by $50 \%(P<0.05)$ at I6 and I8, remained slightly elevated at R10 $(+30 \%, P=0.06)$, and were completely normalized at R15 and R20 in gastrocnemius muscle from the immobilized leg compared with control muscle. Accordingly, immobilization induced an accumulation of Ub-protein conjugates from I4 $(+40 \%, P<0.05)$, which remained elevated during the whole immobilization period $(+64 \%$ at I8, $P<0.05)$. The amount of polyubiquitinated proteins was normalized at R10 (Fig. 3, $B$ and $C$ ). In addition, Fig. $4 A$ shows that the chymotrypsin-like activity of the proteasome measured after separation of the proteasome complexes on a $10-40 \%$ sucrose gradient increased at I8 in immobilized muscles compared with controls. The global induction of the chymotrypsin-like activity of the proteasome was calculated for each time point and Fig. $4 B$ shows that proteasome activity increased by 65 and $138 \%$ at I6 and I8, respectively, and was totally suppressed at R10 in muscles from the immobilized leg compared with control muscles.

Regulation of myogenic marker myf5 and apoptosis. Atrophy and recovery of muscles were associated not only with parallel modifications in the Ub-proteasome-dependent proteolytic pathway, but also with variations in regeneration and apoptosis processes. Myf5 is a one of the major transcription factors involved in muscle regeneration (14) and is considered as an early maker of satellite cells differentiation. Figure $5 \mathrm{~A}$ shows that the protein levels of the myogenic marker myf5 decreased in gastrocnemius muscles during the whole immobilization period from I4 ( $-30 \%, P<0.05)$ to I8 $(-33 \%, P<$ 0.05 ) (Fig. 3A). This was associated with a large increase in the number of apoptotic nuclei $(+97 \%, P<0.0001)$ at I8 (Fig. $5 B$ ). Myf5 protein levels were rapidly normalized to control values as soon as R10 (Fig. 5A).

Regulation of the apoptotic mitochondrial pathway. Because of the implication of the apoptotic mitochondrial pathway in disuse-induced muscle atrophy (33), further studies were performed on this pathway. Apoptosomes are complexes resulting from the association of caspase-9, cytochrome $c$, and APAF-1
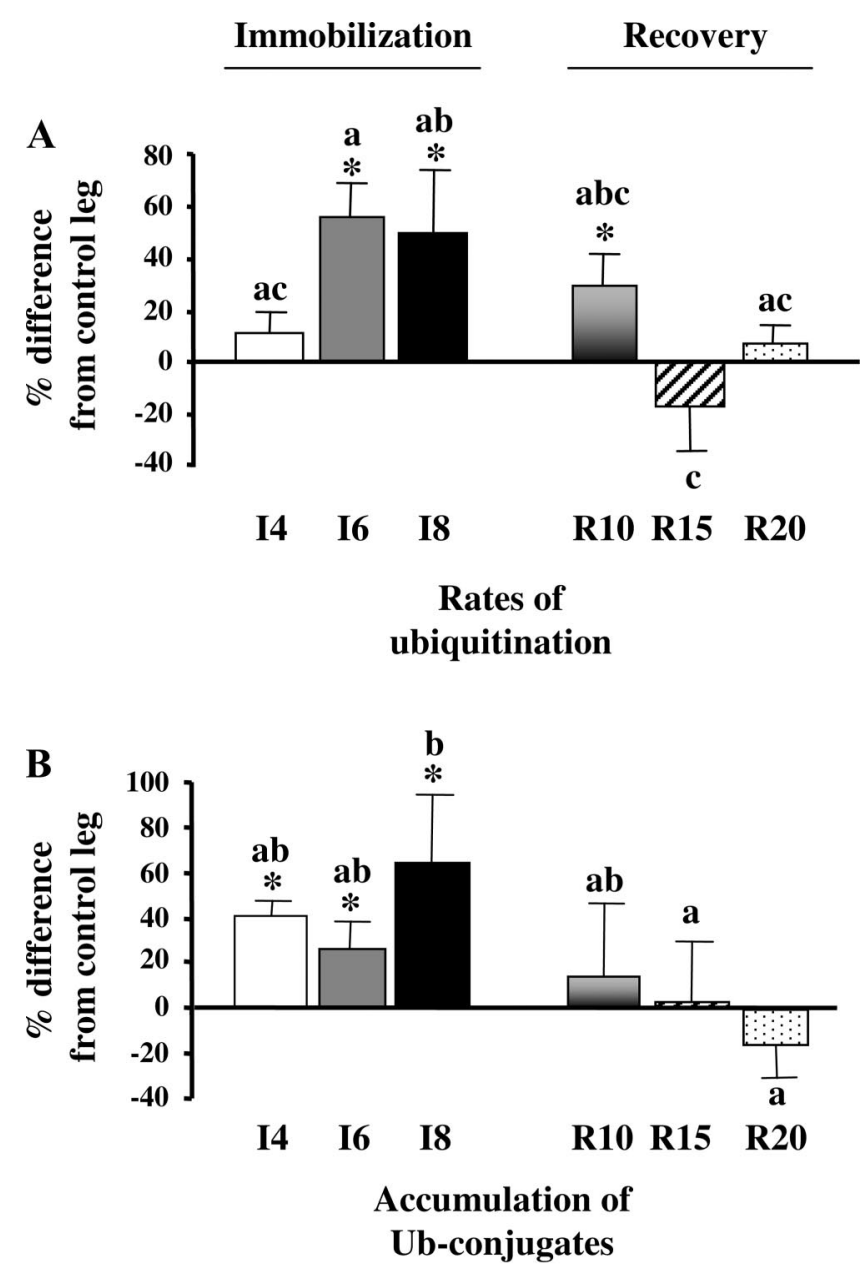

C

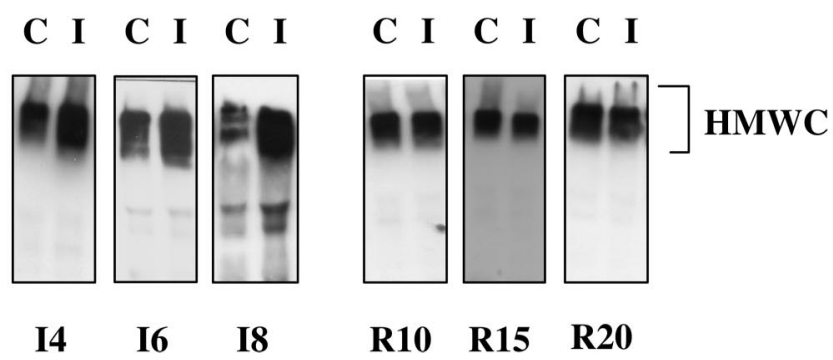

Fig. 3. Ubiquitination rates and ubiquitin-protein conjugates were rapidly increased and normalized when muscle atrophies and recovers, respectively. Rates of ubiquitination $(A)$ were measured by using the soluble fraction of the gastrocnemius muscle. The formation of high molecular weight biotinylatedubiquitin (Ub) conjugates (HMWC) was followed as described in EXPERIMENTAL PROCEDURES. The diagram shows the induction or the repression of ubiquitination rates (i.e., the slopes of best fit of biotinylated-Ub bound to HMWC) between immobilized and control muscles. Accumulation of Ub conjugates $(B)$ was assessed on $25 \mu \mathrm{g}$ of myofibrillar proteins by Western blotting using an antibody that recognizes specifically polyUb chains. Signals were quantified by using the Image $J$ software and normalized against the amount of proteins (determined following Ponceau Red staining) to correct for uneven loading. Representative immunoblots are also shown $(C)$. C, control; I, immobilized. Data are expressed as \% difference from control leg and are means \pm SE (vertical bars) for $n=5$ rats per group. Differences between control and immobilized muscles at each time point were assessed via paired Student's $t$-test $(* P<0.05)$. The evolution of the differences during the immobilization and the recovery was determined by 1-way ANOVA. Bars with different letters are significantly different from each other $(P<0.05)$. 


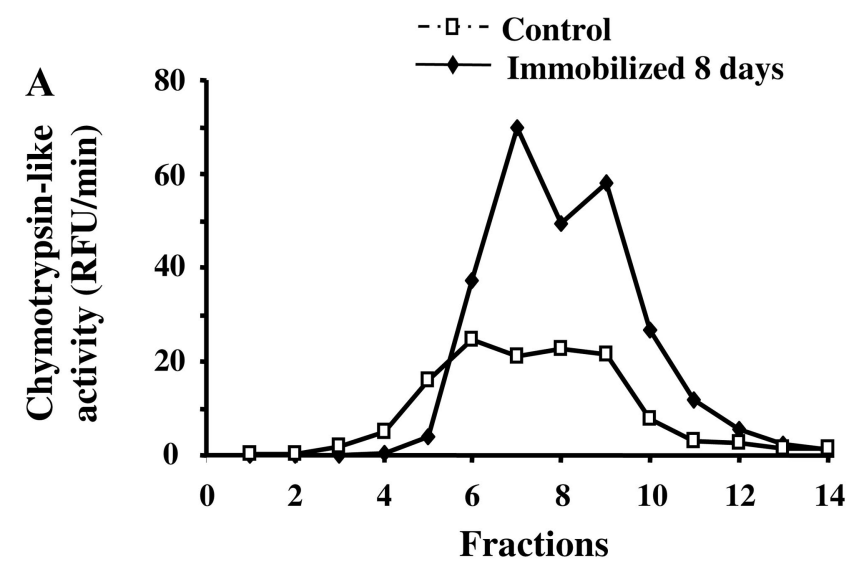

Immobilization

Recovery

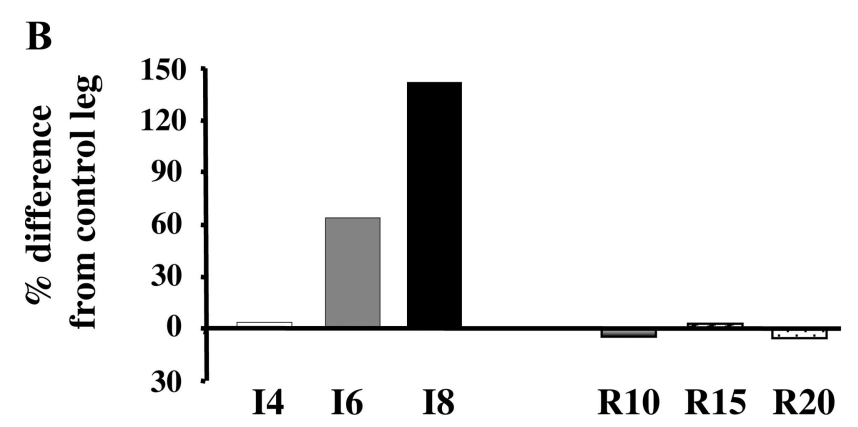

Fig. 4. Regulation of proteasome activity in muscles during immobilization and recovery periods. Proteins from pooled gastrocnemius muscles were separated onto a $10-40 \%$ sucrose gradient. The chymotrypsin-like activity of the proteasome was then measured by using a fluorogenic substrate on the resulting fractions as described in EXPERIMENTAL PROCEDURES. The profiles show the slopes of best fit of relative fluorescence units (RFU) accumulated vs. time for the chymotrypsin-like activity of the proteasome in each fraction from immobilized and control gastrocnemius muscle extracts at I8 (A). These profiles were obtained at each time points of the immobilization or the recovery periods and the area under the curve was calculated to show the global induction or repression of the chymotrypsin-like activity of the proteasome in immobilized muscles $(B)$.

molecules and are known to copurify on $10-40 \%$ sucrose gradients with proteasome complexes (8). We have adapted a method to measure the activity of the apoptosome on skeletal muscle extracts and showed that the apoptosome-linked caspase-9 activity increased in immobilized muscles compared with controls at I8 (+112\%) (Fig. 6A). Figure 6B shows that the protein levels for APAF-1 and caspase- 9 in fractions containing the apoptosome-linked caspase- 9 activity increased in immobilized muscles at I8 compared with controls, suggesting an increase in apoptosome abundance. As in Fig. 4, the global induction of the apoptosome-linked caspase- 9 activity was calculated at each time point. Figure $6 C$ shows that the apoptosome activity increased by 77 and $115 \%$ in immobilized muscles compared with control muscles at I6 and I8, respectively. The apoptosome activity was downregulated at R10, $\mathrm{R} 15$, and R20 by 28,18 , and $16 \%$, respectively (Fig. $6 C$ ).

Figure $7 A$ shows that the total activity of caspase- 3 increased in immobilized muscles at 18 by $75 \%(P<0.05)$, without any modification at I4 and I6. The increased caspase-3 activity, which still prevails at R10 $(+35 \%, P<0.05)$ was, however, significantly reduced between I8 and R10 $(-53 \%, P<0.05)$. In addition, the caspase- 3 activity was downregulated $(-20 \%$, $P<0.05$ ) below basal levels at R15 and normalized at R20 (Fig. $7 A$ ). The total activity of caspase- 9 increased at I8 by $45 \%(P<0.05)$, was suppressed at R10, slightly downregulated below basal levels at R15 and R20 ( $-20 \%$ and $-15 \%$, not significant), and normalized at R30 (Fig. 7B). In addition, protein levels for the antiapoptotic protein XIAP decreased at I8 $(-26 \%, P<0.05)$ when caspase activities were activated, normalized at R10, increased at R15 $(+46 \%, P<0.05)$ when caspase activities were downregulated, and almost normalized at R20 (+28\%, not significant) (Fig. 7C).

\section{DISCUSSION}

This study aimed to characterize the mechanisms underlying muscle atrophy and recovery following immobilization. Our data demonstrate 1 ) that the mitochondria-associated pathway is activated concomitantly with increased Ub-proteasome proteolysis during immobilization and 2) that these two pathways are sequentially normalized during muscle recovery following disuse. We showed that after cast removal the Ub-proteasome pathway is rapidly normalized when muscle atrophy stabilized, whereas the mitochondria-associated apoptotic pathway is later downregulated when muscle recovers, suggesting that both pathways are implicated in efficient muscle recovery.

We report here that skeletal muscles quickly atrophy but slowly recover in rats subjected to unilateral hindlimb casting. This is clearly different from muscle mass recovery during reloading after hindlimb suspension $(23,32,38)$ and is of
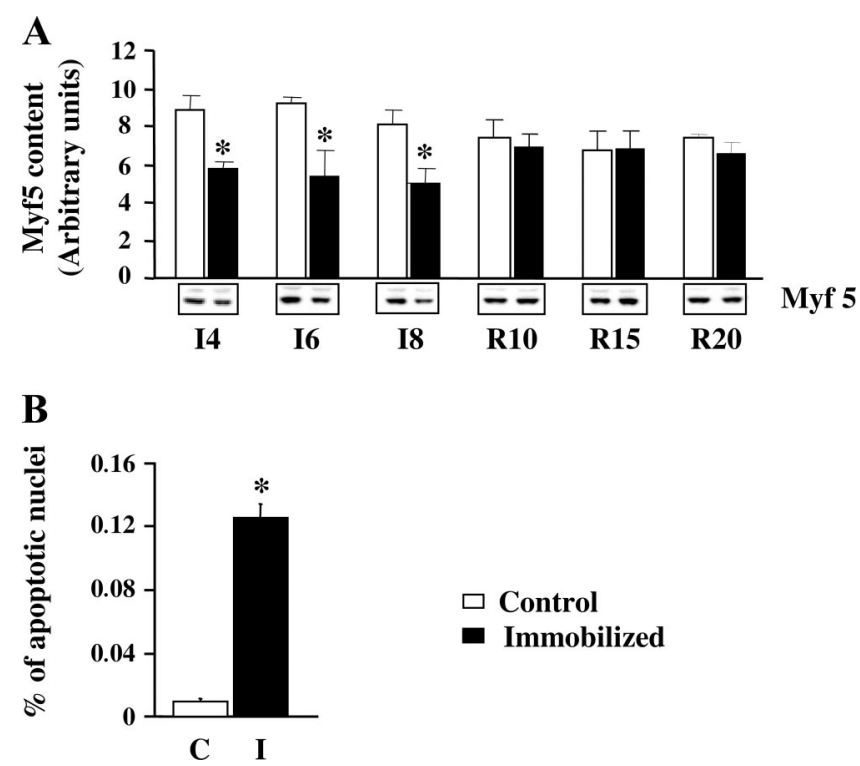

Fig. 5. Myogenic markers were repressed in gastrocnemius muscles during immobilization and rapidly normalized during recovery. Protein levels for Myf5 (A) were assessed by Western blotting as described in EXPERIMENTAL PROCEDURES. Signals were quantified and normalized against the amount of proteins (determined following Ponceau Red staining) to correct for uneven loading. Representative immunoblots are also shown. The number of apoptotic nuclei $(B)$ were monitored on cross sections of gastrocnemius muscles at I8 by using a terminal deoxynucleotidyl transferase biotin-dUTP nick-end labeling (TUNEL) fluorescent detection kit. Values are corrected with the total number of nuclei and expressed in \% of apoptotic nuclei. Values are means \pm SE (vertical bars) for $n=5$ rats per group. ${ }^{*} P<0.05$ vs. control muscles using the paired Student's $t$-test. 


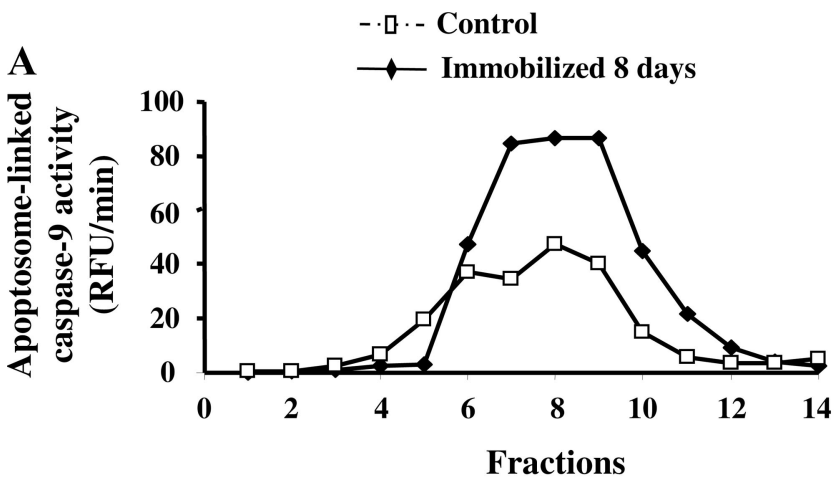

B
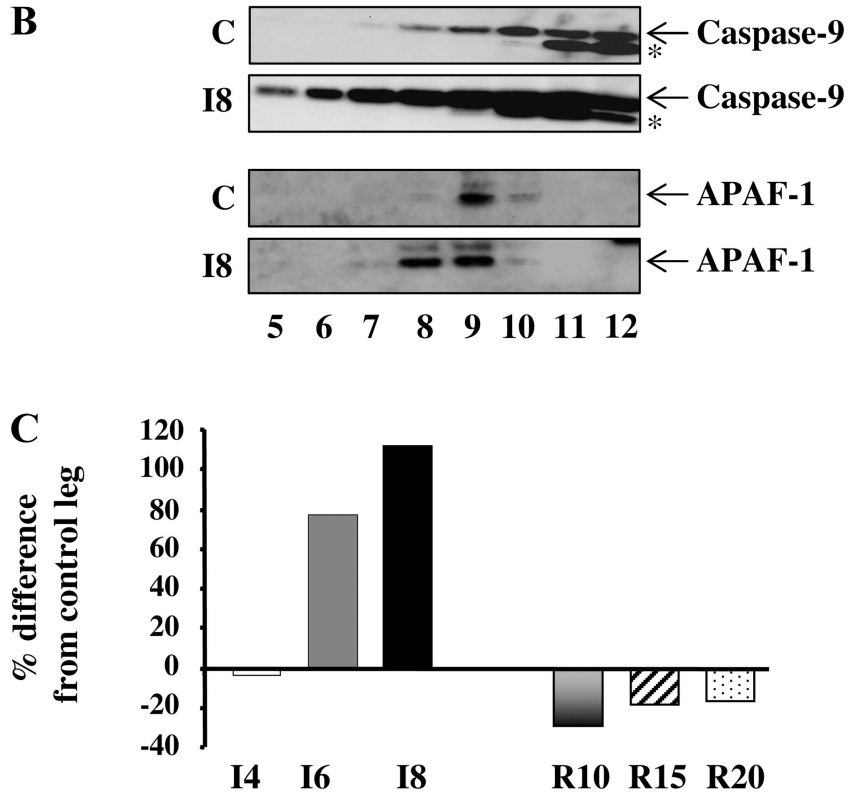

Fig. 6. Regulation of apoptosome activity in muscles during immobilization and recovery periods. Apoptosome complexes copurify with proteasomes onto $10-40 \%$ sucrose gradients. The apoptosome-linked caspase- 9 activity was therefore assessed on the same fractions obtained from the proteasomes preparation (see Fig. 5 legend) by using a fluorogenic substrate as described in EXPERIMENTAL PROCEDURES. The profiles show the slopes of best fit of RFU accumulated vs. time for the apoptosome-linked caspase- 9 activity in each fraction from immobilized and control gastrocnemius muscles extracts at I8 (A). The abundance of apoptosome was assessed by Western blots on the fractions that contain the peak of proteasome and apoptosome activities using caspase-9 and APAF-1 antibodies. Representative immunoblots are shown (B; *nonspecific signal). The profiles of apoptosome-linked caspase-9 activity were obtained for immobilized and control muscles at each time point of the immobilization or the recovery and the area under the curve was calculated to represent the global induction or repression of the apoptosome activity in immobilized muscles $(C)$.

obvious clinical interest since this may be more akin to disuse that follows fractures and bed rest-associated pathologies. The studied muscles did not atrophy to the same extent during immobilization and did not recover according to the same kinetics. In fact, EDL and tibialis anterior muscles atrophied less than gastrocnemius and soleus muscles after 8 days of immobilization. This observation may be explained in part by different fiber-type composition and position of immobilization between muscles. Immobilization decreases the percentage of type I fibers and increases the percentage of type II fibers (19). Gastrocnemius and soleus muscles are composed of

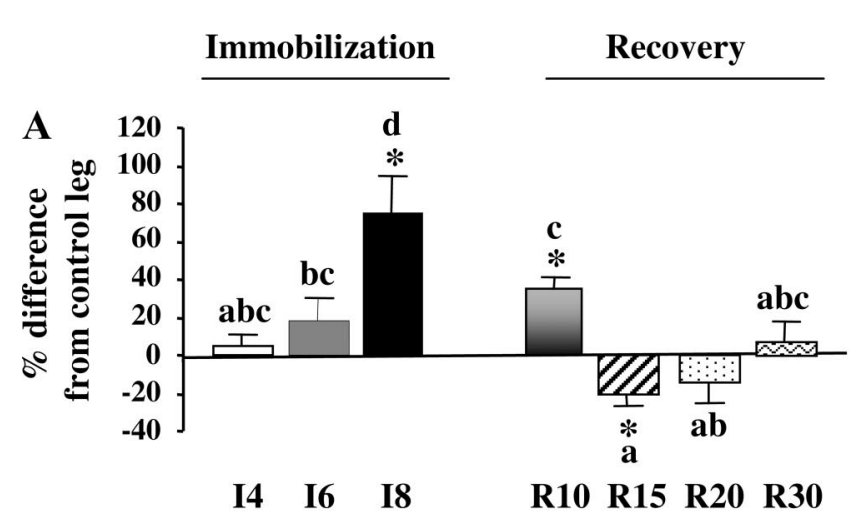

Caspase-3

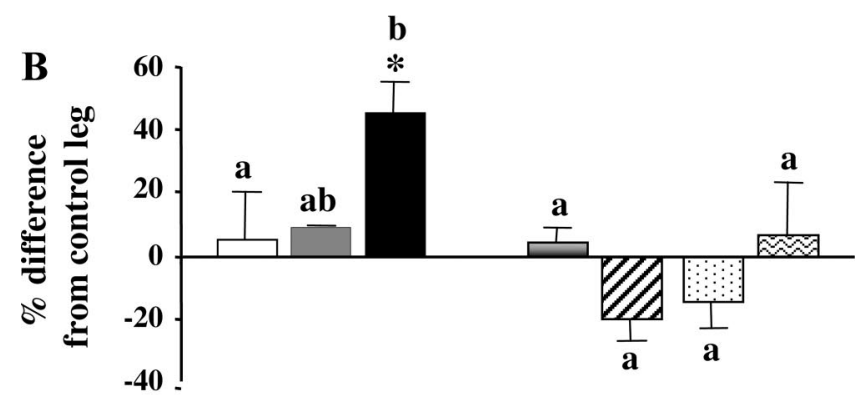

$\begin{array}{lll}\text { I4 } & \text { I6 } & \text { I8 }\end{array}$

R10 R15 R20 R30

Caspase-9 activity

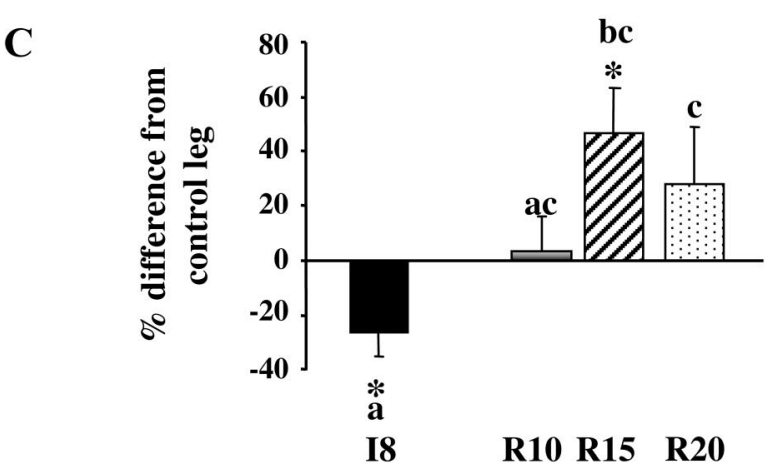

XIAP content

Fig. 7. Muscle caspase-3 and -9 activities were upregulated during immobilization and downregulated during recovery before complete normalization. Caspase-3 $(A)$ and total caspase-9 $(B)$ activities were assessed on gastrocnemius muscle extracts using fluorogenic substrates as described in EXPERIMENTAL PROCEDURES. Protein levels for X-linked inhibitory apoptotic protein (XIAP; $C$ ) were assessed on $50 \mu \mathrm{g}$ of gastrocnemius muscle proteins by Western blotting as described in EXPERIMENTAL PROCEDURES. Signals were quantified and normalized against the amount of proteins (determined following Ponceau Red staining) to correct for uneven loading. Representative immunoblots are also shown. Data are expressed as \% difference from control leg and are means \pm SE (vertical bars) for $n=5$ rats per group. Differences between control and immobilized muscles at each time point were assessed by paired Student's $t$-test $(* P<0.05)$. The evolution of the differences during immobilization and recovery was determined by 1-way ANOVA. Bars with different letters are significantly different from each other $(P<0.05)$. 
mixed (I, IIA, and IIB) and oxidative (type I) fibers, respectively, whereas EDL and tibialis anterior muscles almost lack type I fibers. This may make gastrocnemius and soleus muscles more sensitive to the disuse-induced atrophy than EDL and tibialis anterior muscles. In our study, the animal leg was immobilized in plantar extension so that gastrocnemius and soleus muscles were held in a shortened position, whereas EDL and tibialis anterior muscles were held in a stretched position. The greater atrophy of the soleus and the gastrocnemius muscles observed in this work is in complete agreement with previous data $(6,16)$, showing that muscle atrophy is greater when muscle are immobilized in a shortened position. A noteworthy difference also lay in the worsening of the tibialis anterior muscle wasting between I8 and R10, whereas the atrophy of the three other muscles stabilized within the same period. Immobilization induces an increased density of connective tissue (21), which is accentuated when a stretched position is applied (28). Thus the stretched tibialis anterior muscle may exhibit more extensive connective tissue damage compared with the shortened soleus or gastrocnemius muscles during immobilization. This may imply that these connective tissues should be removed immediately after cast removal and could explain the sustained tibialis anterior muscle atrophy between I8 and R10 before subsequent recovery can be initiated. Again, these observations support that the lengthening and shortening of the tibialis anterior/EDL vs. gastrocnemiussoleus muscle is a predominant factor for the extent of atrophy during immobilization but also for the worsening of the tibialis anterior muscle atrophy during early recovery.

An increased number of nuclei undergoing apoptosis and expression of proapoptotic genes including Bax, caspase-3, apoptosis-inducing factor, and APAF-1 prevail during disuse (13, 36; this study). We show here that the balance between apoptosis and differentiation-regeneration processes is altered during immobilization. Indeed, DNA fragmentation increased and the protein levels for the differentiation factor myf5 decreased at I8 in immobilized muscles. The number of apoptotic nuclei was measured on a cross section of the central part of the gastrocnemius muscle whereas the protein levels for myf5 were assessed on a homogenate of the remaining muscle. The gastrocnemius muscle being heterogeneous in fiber-type composition depending on the region considered, the increased apoptotic nuclei observed in the central part of the immobilized muscle at I8 may differ depending on fiber-type-specific alterations. Myf5 expression is greatly induced during satellite cell activation (12). Therefore, our data suggest that the decrease of myf5 expression could result from a diminished capacity of satellite cells to differentiate following immobilization. In addition, the progressive decline in the satellite cell pool has been hypothesized to result from satellite cell apoptosis (18). Thus we cannot exclude that the increased number of apoptotic nuclei referred to satellite cell undergoing apoptosis and that the decreased myf5 protein levels resulted from a decreased amount of satellite cells.

We also show, for the first time to our knowledge, that the mitochondrial apoptotic pathway was enhanced during immobilization. We indeed report an increased activity and assembly of this complex during immobilization, caspase- 9 and APAF-1 protein levels being elevated in immobilized muscles compared with controls. In addition, protein levels for the proapoptotic molecule Smac/Diablo increased during immobilization (data not shown), whereas those for XIAP decreased. XIAP acts as an E3 ligase toward mature caspase- 9 and Smac to control apoptosis (30). Therefore, our data suggest that the levels of proapoptotic and antiapoptotic proteins shifted the balance of degeneration-regeneration processes to the entry into apoptosis during immobilization and likely contributed to skeletal muscle wasting. This study also shows that the mitochondria-associated apoptotic pathway was upregulated concomitantly with the Ub-proteasome-dependent system during immobilization. The activation of both proteolytic and apoptotic pathways suggest that these two processes may share common signals. Immobilization increases contributors to oxidative stress and is usually accompanied by the activation of inflammatory cells in skeletal muscle (3), which could trigger increased proteasome-dependent proteolysis, apoptosis, and atrophy in skeletal muscle during immobilization.

The disuse-induced atrophy of the gastrocnemius muscles results from an activation of proteolysis but also from a decreased protein synthesis $(16,42)$. The activation of proteolysis is in accordance with studies in human beings. A recent study showed that 3-methylhistidine content increased in muscle from men subjected to unilateral lower limb suspension (41). Increased muscle mRNA levels for MuRF-1 or MAFbx/ atrogin1 also prevailed in humans during bed rest (35) or in complete diaphragm inactivity (26). Our data also show that the recovery of the gastrocnemius muscle mass is still prevailing at R40 independently of adaptations in proteolysis and apoptosis. Indeed, gastrocnemius muscles were still atrophied at R20 while both Ub-proteasome-dependent and the mitochondria-associated apoptotic pathways were normalized. This implies that protein synthesis should be stimulated after R20 to allow muscle mass gain. This is in accordance with our previous observations showing that the remodeling of reloaded soleus muscles is characterized by increased protein synthesis in the late stages of recovery (38). Altogether, these data indicate that manipulating both protein breakdown and protein synthesis should improve efficient muscle recovery.

We also report here that both the Ub-proteasome-dependent and the mitochondria-associated apoptotic pathways are sequentially regulated after cast removal, thus likely contributing to skeletal muscle recovery. The activity of the Ub-proteasome-dependent pathway was rapidly normalized when muscle atrophy was stabilized, whereas apoptotic processes were downregulated when muscle starts to recover before complete normalization only at 20 days of recovery. This sequential normalization of the Ub-proteasome-proteolytic and the mitochondria-associated apoptotic pathways suggests a possible cooperation to ensure proper muscle mass recovery. The early step would consist of stabilization of muscle atrophy through the normalization of proteolysis in immobilized muscles and the second step of muscle mass gain through the downregulation of apoptotic processes at R15. Indeed, apoptotic mechanisms have been suggested to be involved in the modulation of myonuclei number during chronic unloading and subsequent reloading in rats (32) but also during differentiation of $\mathrm{C} 2 \mathrm{C} 12$ myoblasts (14). This suggests that the regulation of the mitochondria-associated apoptotic pathway may be of major importance to initiate myogenesis and promote muscle recovery.

In conclusion, we have shown that the mitochondria-associated apoptotic pathway is activated concomitantly with the Ub-proteasome-dependent system during cast immobilization, 
suggesting that both pathways play a key role in skeletal muscle atrophy. We also demonstrate that these pathways are regulated during skeletal muscle recovery with a rapid normalization or even a downregulation below basal levels. Furthermore, our data suggest a two-stage process in which the Ub-proteasome-dependent pathway is first normalized and apoptotic processes are later sequentially downregulated and normalized during recovery following immobilization.

\section{ACKNOWLEDGMENTS}

We thank Arlette Cissoire, Benoit Cohade, Christian Lafarge, and Alexandre Teynie from the UE231 (INRA Clermont-Ferrand-Theix, France) for excellent assistance during animal experimentations. We also thank Philippe Paul (Service de Kinésithérapie de la Clinique de la Chataigneraie, Beaumont, France) and Michèle Balage from the UMR1019 (INRA Clermont-FerrandTheix, France) for helpful discussions.

\section{GRANTS}

This study was supported by grants from the Institut National de la Recherche Agronomique and the Association Française contre les Myopathies. E. Vazeille was supported by a $\mathrm{PhD}$ fellowship from the Ministère de l'Enseignement Supérieur et de la Recherche.

\section{REFERENCES}

1. Allen DL, Linderman JK, Roy RR, Bigbee AJ, Grindeland RE, Mukku V, Edgerton VR. Apoptosis: a mechanism contributing to remodelling of skeletal muscle in response to hindlimb unweighting. Am J Physiol Cell Physiol 273: C579-C587, 1997.

2. Attaix D, Ventadour S, Codran A, Bechet D, Taillandier D, Combaret L. The ubiquitin-proteasome system and skeletal muscle wasting. Essays Biochem 41: 173-186, 2005.

3. Bar-Shai M, Carmeli E, Ljubuncic P, Reznick AZ. Exercise and immobilization in aging animals: the involvement of oxidative stress and NF-kappaB activation. Free Radic Biol Med 44: 202-214, 2008.

4. Berthon P, Duguez S, Favier FB, Amirouche A, Feasson L, Vico L, Denis C, Freyssenet D. Regulation of ubiquitin-proteasome system, caspase enzyme activities, and extracellular proteinases in rat soleus muscle in response to unloading. Pflügers Arch 454: 625-633, 2007.

5. Bodine SC, Latres E, Baumhueter S, Lai VK, Nunez L, Clarke BA, Poueymirou WT, Panaro FJ, Na E, Dharmarajan K, Pan ZQ, Valenzuela DM, DeChiara TM, Stitt TN, Yancopoulos GD, Glass DJ. Identification of ubiquitin ligases required for skeletal muscle atrophy. Science 294: 1704-1708, 2001.

6. Booth FW. Effect of limb immobilization on skeletal muscle. J Appl Physiol 52: 1113-1118, 1982.

7. Borisov AB, Carlson BM. Cell death in denervated skeletal muscle is distinct from classical apoptosis. Anat Rec 258: 305-318, 2000.

8. Cain K, Brown DG, Langlais C, Cohen GM. Caspase activation involves the formation of the aposome, a large (approximately $700 \mathrm{kDa}$ ) caspase-activating complex. J Biol Chem 274: 22686-22692, 1999.

9. Charge SB, Rudnicki MA. Cellular and molecular regulation of muscle regeneration. Physiol Rev 84: 209-238, 2004.

10. Combaret L, Dardevet D, Rieu I, Pouch MN, Bechet D, Taillandier D, Grizard J, Attaix D. A leucine-supplemented diet restores the defective postprandial inhibition of proteasome-dependent proteolysis in aged rat skeletal muscle. J Physiol 569: 489-499, 2005.

11. Combaret L, Tilignac T, Claustre A, Voisin L, Taillandier D, Obled C, Tanaka K, Attaix D. Torbafylline (HWA 448) inhibits enhanced skeletal muscle ubiquitin-proteasome-dependent proteolysis in cancer and septic rats. Biochem J 361: 185-192, 2002.

12. Cooper RN, Tajbakhsh S, Mouly V, Cossu G, Buckingham M, ButlerBrowne GS. In vivo satellite cell activation via Myf5 and MyoD in regenerating mouse skeletal muscle. J Cell Sci 112: 2895-2901, 1999.

13. Degens H, Alway SE. Control of muscle size during disuse, disease, and aging. Int J Sports Med 27: 94-99, 2006.

14. Fernando P, Kelly JF, Balazsi K, Slack RS, Megeney LA. Caspase 3 activity is required for skeletal muscle differentiation. Proc Natl Acad Sci USA 99: 11025-11030, 2002.

15. Gayraud-Morel B, Chrétien F, Flamant P, Gomès D, Zammit PS, Tajbakhsh S. A role for the myogenic determination gene Myf5 in adult regenerative myogenesis. Dev Biol 312: 13-28, 2007.
16. Goldspink DF. The influence of immobilization and stretch on protein turnover of rat skeletal muscle. J Physiol 264: 267-282, 1977.

17. Gomes MD, Lecker SH, Jagoe RT, Navon A, Goldberg AL. Atrogin-1, a muscle-specific F-box protein highly expressed during muscle atrophy. Proc Natl Acad Sci USA 98: 14440-14445, 2001.

18. Hawke TJ, Garry DJ. Myogenic satellite cells: physiology to molecular biology. J Appl Physiol 91: 534-551, 2001.

19. Hortobagyi T, Dempsey L, Fraser D, Zheng D, Hamilton G, Lambert J, Dohm L. Changes in muscle strength, muscle fibre size and myofibrillar gene expression after immobilization and retraining in humans. $J$ Physiol 524: 293-304, 2000.

20. Ikemoto M, Nikawa T, Takeda S, Watanabe C, Kitano T, Baldwin KM, Izumi R, Nonaka I, Towatari T, Teshima S, Rokutan K, Kishi K. Space shuttle flight (STS-90) enhances degradation of rat myosin heavy chain in association with activation of ubiquitin-proteasome pathway. FASEB J 15: 1279-1281, 2001.

21. Jarvinen TA, Jozsa L, Kannus P, Jarvinen TL, Jarvinen M. Organization and distribution of intramuscular connective tissue in normal and immobilized skeletal muscles. An immunohistochemical, polarization and scanning electron microscopic study. J Muscle Res Cell Motil 23: 245-254, 2002.

22. Jones SW, Hill RJ, Krasney PA, O'Conner B, Peirce N, Greenhaff PL. Disuse atrophy and exercise rehabilitation in humans profoundly affects the expression of genes associated with the regulation of skeletal muscle mass. FASEB J 18: 1025-1027, 2004.

23. Kasper CE, White TP, Maxwell LC. Running during recovery from hindlimb suspension induces transient muscle injury. J Appl Physiol 68: 533-539, 1990.

24. Krawiec BJ, Frost RA, Vary TC, Jefferson LS, Lang CH. Hindlimb casting decreases muscle mass in part by proteasome-dependent proteolysis but independent of protein synthesis. Am J Physiol Endocrinol Metab 289: E969-E980, 2005.

25. Kujawa M, Baran W, Jankowska-Steifer E. Quantitative ultrastructural changes in satellite cells of rats immobilized after soleus muscle denervation. Exp Mol Pathol 78: 78-85, 2005.

26. Levine S, Nguyen T, Taylor N, Friscia ME, Budak MT, Rothenberg P, Zhu J, Sachdeva R, Sonnad S, Kaiser LR, Rubinstein NA, Powers SK, Shrager JB. Rapid disuse atrophy of diaphragm fibers in mechanically ventilated humans. N Engl J Med 358: 1327-1335, 2008.

27. Lowry OH, Rosebrough NJ, Farr AL, Randall RJ. Protein measurement with the Folin phenol reagent. J Biol Chem 193: 265-275, 1951.

28. Mattiello-Sverzut AC, Carvalho LC, Cornachione A, Nagashima M, Neder L, Shimano AC. Morphological effects of electrical stimulation and intermittent muscle stretch after immobilization in soleus muscle. Histol Histopathol 21: 957-964, 2006.

29. Moresi V, Pristerà A, Scicchitano BM, Molinaro M, Teodori L, Sassoon D, Adamo S, Coletti D. Tumor necrosis factor-alpha inhibition of skeletal muscle regeneration is mediated by a caspase-dependent stem cell response. Stem Cells 26: 997-1008, 2008.

30. Morizane Y, Honda R, Fukami K, Yasuda H. X-linked inhibitor of apoptosis functions as ubiquitin ligase toward mature caspase-9 and cytosolic Smac/DIABLO. J Biochem (Tokyo) 137: 125-132, 2005.

31. Nicks DK, Beneke WM, Key RM, Timson BF. Muscle fibre size and number following immobilisation atrophy. J Anat 163: 1-5, 1989.

32. Oishi Y, Ogata T, Yamamoto KI, Terada M, Ohira T, Ohira Y, Taniguchi K, Roy RR. Cellular adaptations in soleus muscle during recovery after hindlimb unloading. Acta Physiol (Oxf) 192: 381-395, 2008.

33. Powers SK, Kavazis AN, McClung JM. Oxidative stress and disuse muscle atrophy. J Appl Physiol 102: 2389-2397, 2007.

34. Rajapurohitam V, Bedard N, Wing SS. Control of ubiquitination of proteins in rat tissues by ubiquitin conjugating enzymes and isopeptidases. Am J Physiol Endocrinol Metab 282: E739-E745, 2002.

35. Salanova M, Schiffl G, Püttmann B, Schoser BG, Blottner D. Molecular biomarkers monitoring human skeletal muscle fibres and microvasculature following long-term bed rest with and without countermeasures. J Anat 212: 306-318, 2008.

36. Siu PM, Bryner RW, Martyn JK, Alway SE. Apoptotic adaptations from exercise training in skeletal and cardiac muscles. FASEB $J$ 18: 1150-1152, 2004.

37. Siu PM, Pistilli EE, Alway SE. Apoptotic responses to hindlimb suspension in gastrocnemius muscles from young adult and aged rats. Am J Physiol Regul Integr Comp Physiol 289: R1015-R1026, 2005.

38. Taillandier D, Aurousseau E, Combaret L, Guezennec CY, Attaix D. Regulation of proteolysis during reloading of the unweighted soleus muscle. Int J Biochem Cell Biol 35: 665-675, 2003. 
39. Taillandier D, Aurousseau E, Meynial-Denis D, Bechet D, Ferrara M, Cottin P, Ducastaing A, Bigard X, Guezennec CY, Schmid HP, Attaix D. Coordinate activation of lysosomal, $\mathrm{Ca}^{2+}$-activated and ATP-ubiquitin-dependent proteinases in the unweighted rat soleus muscle. Biochem J 316: 65-72, 1996.

40. Tawa NE Jr, Odessey R, Goldberg AL. Inhibitors of the proteasome reduce the accelerated proteolysis in atrophying rat skeletal muscles. J Clin Invest 100: 197-203, 1997.

41. Tesch PA, von Walden F, Gustafsson T, Linnehan RM, Trappe TA. Skeletal muscle proteolysis in response to short-term unloading in humans. J Appl Physiol 102: 902-906, 2008.
42. Thomason DB, Booth FW. Atrophy of the soleus muscle by hindlimb unweighting. J Appl Physiol 68: 1-12, 1990.

43. Urso ML, Scrimgeour AG, Chen YW, Thompson PD, Clarkson PM. Analysis of human skeletal muscle after $48 \mathrm{~h}$ immobilization reveals alterations in mRNA and protein for extracellular matrix components. J Appl Physiol 101: 1136-1148, 2006.

44. Wing SS, Haas AL, Goldberg AL. Increase in ubiquitin-protein conjugates concomitant with the increase in proteolysis in rat skeletal muscle during starvation and atrophy denervation. Biochem J 307: 639-645, 1995.

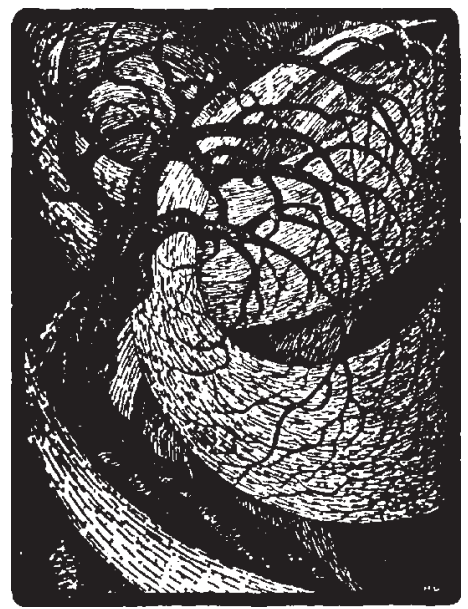

